\title{
Electrosynthesis of poly-o-diaminobenzene on the Prussian Blue modified electrodes for improvement of hydrogen peroxide transducer characteristics
}

\author{
Lilia V. Lukachova ${ }^{a}{ }^{*}$, Elena A. Kotel'nikova ${ }^{a}$, Daniele D'Ottavi ${ }^{b}$, Egor A. Shkerin ${ }^{a}$, \\ Elena E. Karyakina ${ }^{\mathrm{a}}$, Danila Moscone ${ }^{\mathrm{b}}$, Giuseppe Palleschi ${ }^{\mathrm{b}}$, Antonella Curulli ${ }^{\mathrm{c}}$, \\ Arkady A. Karyakin ${ }^{\text {a }}$ \\ ${ }^{a}$ Faculty of Chemistry, M.V. Lomonosov Moscow State University, 119899 Moscow, Russia \\ ${ }^{\mathrm{b}}$ Dipartimento di Scienze e Tecnologie Chimiche, Universita di Roma 'Tor Vergata', via della Ricerca Scientifica, Rome, Italy \\ ${ }^{\mathrm{c}}$ Centro CNR di Studio per la Elettrochimica e la Chimica Fisica della Interfasi, Rome, Italy
}

Received 1 June 2001; received in revised form 24 August 2001; accepted 3 September 2001

\begin{abstract}
Electropolymerisation of nonconducting polymer, poly-(1,2-diaminobenzene) on the top of Prussian Blue (PB) modified electrode led to significant improvement of resulting hydrogen peroxide transducer selectivity and operational stability. The reported transducer retained $100 \%$ of response during $20 \mathrm{~h}$ under the continuous flow of $0.1 \mathrm{mM} \mathrm{H}_{2} \mathrm{O}_{2}$, and thus improves the stability level in selective peroxide detection by one order of magnitude. The selectivity value of the $\mathrm{PB}-$ poly(1,2-DAB) based $\mathrm{H}_{2} \mathrm{O}_{2}$ sensor in relation to ascorbate is approximately 600 . No signals to acetaminophen and urate were investigated. $\mathrm{PB}$-poly(1,2-diaminobenzene) modified electrode allows the detection of $\mathrm{H}_{2} \mathrm{O}_{2}$ in the flow-injection mode down to $10^{-7} \mathrm{M}$ with the sensitivity $0.3 \mathrm{~A} \mathrm{M}^{-1} \mathrm{~cm}^{-2}$, which is only two times lower compared to the uncovered PB based transducer. (C) 2002 Elsevier Science B.V. All rights reserved.
\end{abstract}

Keywords: Hydrogen peroxide; Prussian Blue; Poly(1,2-diaminobenzene); Interferences

\section{Introduction}

Hydrogen peroxide, being a natural product of oxidase catalysed reaction, can be detected electrochemically. This fact gives rise to analysis of a variety of oxidases substrates, which are important in food industry, clinical diagnostics and environmental monitoring (glucose, lactate, ethanol, glutamate, glycerol, etc.)

The optimal potential range for biosensor operation is from -0.1 to $0.1 \mathrm{~V}(\mathrm{Ag} \mid \mathrm{AgCl})$, where interfering reactions cause only a minor influence on biosensor response $[1,2]$. Up to now, there are only two low potential transducers for hydrogen peroxide reduction: peroxidase and Prussian Blue (PB) modified electrodes. Selective detection of $\mathrm{H}_{2} \mathrm{O}_{2}$ in the presence of oxygen on PB modified electrodes was first announced by Karyakin et al. [3]. Sensitivity

\footnotetext{
* Corresponding author: Tel.: +7-095-9392804; fax: +7-095-9395417.

E-mail address: lukachova@enzyme.chem.msu.ru (L.V. Lukachova).
}

of this transducer is around $1 \mathrm{~A} \mathrm{M}^{-1} \mathrm{~cm}^{-2}$ in steady-state mode [4] and is not inferior to peroxidase electrodes [5]. The relative interference of other electroactive species (ascorbic and uric acid, acetaminophen) to $\mathrm{H}_{2} \mathrm{O}_{2}$ sensing by PB-based electrodes does not exceed 0.05 , while the ratio of the hydrogen peroxide response to those of oxygen is 400-600 [6]. Such advantages of PB based transducer led to development of biosensors for glucose, ethanol and glutamate detection with high sensitivities and low detection limits $(0.1 \mu \mathrm{M})[3,6,7]$.

In some cases, in particular, in clinical diagnostics and food quality control, it is necessary to detect low levels of analytes in the presence of 10-100 higher concentration of ascorbate. Thus, the additional permselective membranes have to be deposited on the transducer surface. The most promising results were achieved using poly-diaminobenzenes $[8-10]$. Such membranes meet the requirements for all-electrochemical sensor fabrication, such as easily controlled thin film electrodeposition on different supports and possibility of enzyme immobilisation during this process. 
Deposition of poly(1,2-diaminobenzene) (poly-1,2-DAB) films was found to cause only minor decrease in response to $\mathrm{H}_{2} \mathrm{O}_{2}$, whereas interferent rejection was higher than $99 \%$ [8].

Electrosynthesis of polymers on PB modified electrodes is possible due to the high oxidising ability of Berlin Green (oxidised state of $\mathrm{PB}$ ) $[10,11]$, and the growth of nonconductive polymers can be controlled investigating redox activity of the inorganic polycrystal. The aim of this work was use of poly(1,2-DAB) for improvement of hydrogen peroxide sensor characteristics.

\section{Experimental}

\subsection{Materials}

All inorganic salts, hydrochloric acid, hydrogen peroxide ( $30 \%$ solution, Reachim, Russia), 1,2-DAB (Calbiochem, CA, USA), uric acid, L-ascorbic acid and acetaminophen from ICN Biomedicals (USA) were of analytical grade.

\subsection{Apparatus}

Electrochemical studies were performed using Solartron Schlumberger Model 1286 (UK). Experiments were carried out in a three-compartment cell containing a Pt net auxiliary electrode and an $\mathrm{Ag} \mid \mathrm{AgCl}$ reference electrode. Glassy carbon disk electrodes (GCE) (GC 2500, Research Institute for Graphite Materials, Moscow, Russia), diameter $1.8 \mathrm{~mm}$, were used as working electrodes. The surface of GCE was polished with alumina powder $(0.3$ and $0.05 \mu \mathrm{m})$ up to a mirror finish. Then, the electrodes were carefully rinsed with water and used immediately. Flow-injection system contained Cole Parmer (USA) peristaltic pump (7519-10), homemade flow-through wall-jet cell with $0.5-\mathrm{mm}$ nozzle positioned at 1-mm distance from the surface of working electrode, homemade injector and Metrohm (Switzerland) potentiostat (641-VA).

\subsection{Procedures}

\subsubsection{Electrodeposition of $P B$}

Electrodeposition of $\mathrm{PB}$ was performed at constant cathodic current of $80 \mu \mathrm{A} \mathrm{cm}{ }^{-2}$ for $50 \mathrm{~s}$ from the initial solution containing $4 \mathrm{mM} \mathrm{K}_{3}\left[\mathrm{Fe}(\mathrm{CN})_{6}\right]$ and $4 \mathrm{mM} \mathrm{FeCl}_{3}$ with $(0.1 \mathrm{M} \mathrm{KCl}+0.1 \mathrm{M} \mathrm{HCl})$ as supporting electrolyte. Posttreatment of modified electrodes was the same as reported earlier [13].

\subsubsection{Electrodeposition of poly(1,2-DAB)}

The PB modified electrodes were placed in deaerated solution of DAB $(5-10 \mathrm{mM})$ in $0.02 \mathrm{M}$ phosphate buf- fer with $0.1 \mathrm{M} \mathrm{KCl}, \mathrm{pH} 6.0$ (PBS). Polymerisation was carried out by cycling the applied potential in the range from -0.05 to $0.7-0.8 \mathrm{~V}$ at a sweep rate of $20 \mathrm{mV} \mathrm{s}^{-1}$ $(10-20$ cycles $)$.

\subsubsection{Analysis of hydrogen peroxide and interferences}

The modified electrodes were poised to $0.0 \mathrm{~V}$ for $10 \mathrm{~min}$ to reach a constant baseline in PBS at flow rate of $1 \mathrm{ml}$ $\min ^{-1} \cdot \mathrm{H}_{2} \mathrm{O}_{2}$, acetaminophen, ascorbic and uric acids were tested in both flow-injection (FI) and continuous flow (CF) modes.

\section{Results and discussion}

\subsection{Electrodeposition of poly(1,2-DAB) on the top of Prussian Blue modified electrodes}

Basing on previously reported data concerning cyclic voltammetric procedure for poly-(1,2-DAB) electrosynthesis [8], we decided to perform its electrodeposition on $\mathrm{PB}$ modified electrodes. Fig. 1 presents cyclic voltammograms of poly(1,2-DAB) synthesis on PB-modified GCE. Irreversible oxidation of 1,2-DAB is observed at high anodic potentials $(\sim 0.7 \mathrm{~V})$. Reduction of PB to Prussian White at $0.13 \mathrm{~V}$ is accomplished by consumption of alkali metal ions [12]. Since cations cross the film-solution interface during oxidation-reduction, the redox activity of $\mathrm{PB}$ is sensitive to appearance of film on its surface. In coarse of 1,2-DAB electropolymerisation, the $\mathrm{PB} /$ Prussian White peaks become broader, and the peak separation value

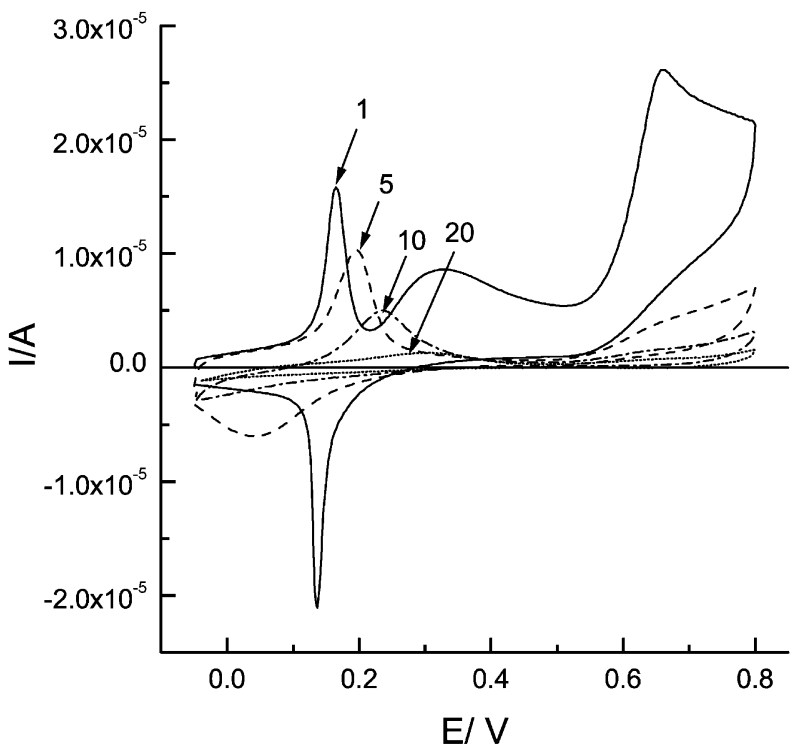

Fig. 1. Cyclic voltammograms of poly-(1,2-DAB) electrodeposition on $\mathrm{PB}$ modified electrode $(0.02 \mathrm{M}$ phosphate buffer with $0.1 \mathrm{M} \mathrm{KCl}$ and $5 \mathrm{mM}$ of 1,2-DAB, pH 6.0; scan rate $20 \mathrm{mV} \mathrm{s}^{-1}$ ). Numerals indicate the numbers of cycles. 
increases (Fig. 1). Thus, the growth of nonconducting films on electroactive surface can be independently controlled.

\subsection{Analytical characteristics of the Prussian Blue based hydrogen peroxide transducers}

PB based transducers were tested under $\mathrm{CF}$ of either $\mathrm{H}_{2} \mathrm{O}_{2}$ or interferents in concentration of $0.1 \mathrm{mM}$. The selectivity in relation to ascorbate was characterized as a ratio of the current of $\mathrm{H}_{2} \mathrm{O}_{2}$ reduction to the current of interferent oxidation. Operational stability was estimated as time, during which the transducer remained $100 \%$ response under $\mathrm{CF}$ of $0.1 \mathrm{mM} \mathrm{H}_{2} \mathrm{O}_{2}$.

Operational characteristics of the transducers were dependent on conditions of poly(1,2-DAB) synthesis, such as the concentration of monomer, the value of anodic switching potential and the number of cycles. In particular, the value of the anodic switching potential affected the morphology of the resulting polymer film. In this study, the best results in terms of $\mathrm{H}_{2} \mathrm{O}_{2}$ response and selectivity were obtained for poly(1,2-DAB) films that were deposited from 5 to $10 \mathrm{mM}$ solution of DAB in PBS using anodic switching potential value of $0.75 \mathrm{~V}$. Selectivity of the $\mathrm{PB}-$ poly(1,2-DAB) sensor is on average 30 times higher compared to the uncovered $\mathrm{PB}$ modified electrode and reached the value of 600 , which is significantly higher compared to the known transducers. No signals were detected to $0.1 \mathrm{mM}$ of uric acid and acetaminophen. Response to ascorbate of the recently reported $\mathrm{PB}-\operatorname{poly}(1,2-$ DAB) -(glucose oxidase) electrode [10] was of $10 \pm 1 \mathrm{~mA}$ $\mathrm{M}^{-1} \mathrm{~cm}^{-2}$ at applied potentials between -0.2 and $0.0 \mathrm{~V}$, which was 10 times higher compared to the currently reported transducer. Thus, in the coarse of this study the optimal procedure for electrodeposition of poly(1,2-DAB) films has been found.

The most significant improvement of the $\mathrm{H}_{2} \mathrm{O}_{2}$ sensor is its highly prolonged operational stability. Under taken experimental conditions (nozzle-to-electrode distance 1 $\mathrm{mm}, 1 \mathrm{ml} \mathrm{min}^{-1}$ flow rate), the uncovered PB modified electrodes were completely stable during $0.5 \mathrm{~h}$. For PBpoly(1,2-DAB) modified electrodes, only after $20 \mathrm{~h}$ was a decrease of the response observed. Since the operational stability of uncovered PB films was already found to be comparative and even higher than that of the other known low-potential $\mathrm{H}_{2} \mathrm{O}_{2}$ transducers, for example, peroxidase electrodes [4], the $\mathrm{PB}-\operatorname{poly}(1,2-\mathrm{DAB})$ sensor improves the stability level in selective peroxide detection by one order of magnitude.

Calibration graphs for hydrogen peroxide detection in the flow-injection mode are presented in Fig. 2. Both sensors based on uncovered conventional $\mathrm{PB}$ and $\mathrm{PB}-$ poly (1,2-DAB) give straight lines in logarithmic plots over four orders of magnitude of $\mathrm{H}_{2} \mathrm{O}_{2}$ concentration. Both transducers allow the detection of hydrogen peroxide down to $10^{-7} \mathrm{M}$ in FI. Sensitivity values calculated from the

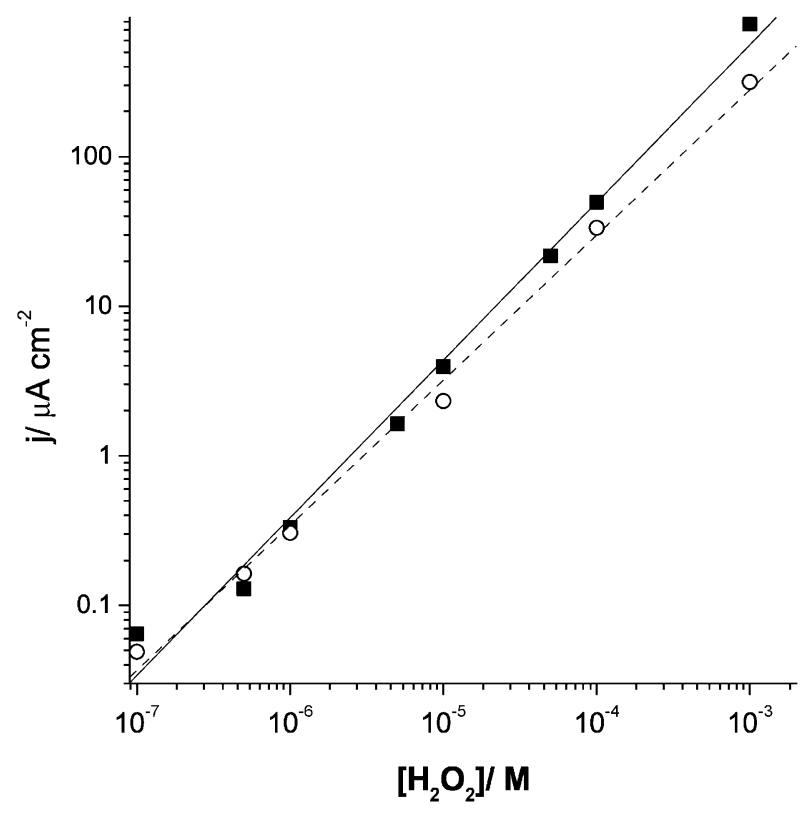

Fig. 2. Calibration plots of hydrogen peroxide detection using ( $\boldsymbol{\square}) \mathrm{PB}$ and (O) PB-poly(1,2-DAB) modified electrodes.

slopes of the straight lines presented in Fig. 2, for uncovered and poly(1,2-DAB) modified $\mathrm{PB}$, are 0.6 and $0.3 \mathrm{~A}$ $\mathrm{M}^{-1} \mathrm{~cm}^{-2}$, respectively. The ratio of sensitivities is similar to the ratio of steady-state responses for the same transducers.

\section{Conclusions}

The attractive performance characteristics of $\mathrm{PB}-$ poly(1,2-DAB) modified electrode are (i) prolonged operational stability improved by one order of magnitude and (ii) selectivity of the $\mathrm{PB}-$ poly $(1,2-\mathrm{DAB})$ based $\mathrm{H}_{2} \mathrm{O}_{2}$ transducer in relation to ascorbate is on average 600 , which is much higher compared to the reported systems. Such selectivity provides the possibility to develop the biosensors for use in certain areas of clinical diagnostics (brain research) and food control (juice and wine analysis).

\section{Acknowledgements}

The financial support through INCO Copernicus Project IC15CT980906 and INTAS Project 00-273 is greatly acknowledged.

\section{References}

[1] J. Wang, P.V.A. Pamidi, D.S. Park, Sol-gel-derived metal-dispersed carbon composite amperometric biosensors, Electroanalysis 9 (1997) $52-55$. 
[2] L. Gorton, Carbon paste electrodes modified with enzymes, tissues and cells, Electroanalysis 7 (1995) 23-45.

[3] A.A. Karyakin, O.V. Gitelmaher, E.E. Karyakina, A high-sensitive glucose amperometric biosensor based on Prussian Blue modified electrodes, Anal. Lett. 27 (1994) 2861-2869.

[4] A. Karyakin, Prussian Blue and its analogues: electrochemistry and analytical applications, Electroanalysis 13 (2001) 813-819.

[5] T. Ruzgas, E. Csöregi, J. Emnèus, L. Gorton, G. Marko-Varga, Peroxidase-modified electrodes: fundamentals and applications, Anal. Chim. Acta 330 (1996) 123-138.

[6] A.A. Karyakin, E.E. Karyakina, L. Gorton, Amperometric biosensor for glutamate using Prussian Blue based "artificial peroxidase" as a transducer for hydrogen peroxide, Anal. Chem. 72 (2000) $1720-$ 1723.

[7] A.A. Karyakin, E.E. Karyakina, L. Gorton, Prussian Blue based amperometric biosensors in flow-injection analysis, Talanta 43 (1996) $1597-1606$.

[8] A. Curulli, S. Dragulescu, C. Cremisini, G. Palleschi, Bienzyme am- perometric probes for choline and choline esters assembled with nonconducting electrosynthesized polymers, Electroanalysis 13 (2001) $236-242$.

[9] J.P. Lowry, R.D. O'Neill, Partial characterization in vitro of glucose oxidase modified poly(phenylenediamine)-coated electrodes for neurochemical analysis in vivo, Electroanalysis 6 (1994) 369-379.

[10] R. Garjonyte, A. Malinauskas, Amperometric glucose biosensor based on glucose oxidase immobilized in poly $o$-phenylenediamine layer, Sensors Actuators, B 56 (1999) 85-92.

[11] A.A. Karyakin, M.F. Chaplin, Polypyrrole-Prussian Blue films with controlled level of doping: copolymerization of polypyrrole and Prussian Blue, J. Electroanal. Chem. 370 (1994) 301-303.

[12] K. Itaya, I. Uchida, V.D. Neff, Electrochemistry of polynuclear transition metal cyanides: Prussian blue and its analogues, Acc. Chem. Res. 19 (1986) $162-168$.

[13] I.L. de Mattos, L. Gorton, T. Ruzgas, A.A. Karyakin, Sensor for hydrogen peroxide based on Prussian Blue modified electrode: improvement of the operational stability, Anal. Sci. 16 (2000) 795-798. 